\title{
KETERTARIKAN KONSUMEN PADA BRAND AMBASSADOR DAN CITRA MEREK PADA KEPUTUSAN PEMBELIAN
}

\author{
Rozalia ${ }^{1}$, Handayani Rinuastuti ${ }^{2}$, Rusminah $\mathrm{Hs}^{3}$ \\ ${ }^{1}$ Fakultas Ekonomi dan Bisnis Universitas Mataram, rozalia.rl25@gmail.com \\ ${ }^{2}$ Fakultas Ekonomi dan Bisnis Universitas Mataram, nrinuastuti@yahoo.com \\ ${ }^{3}$ Fakultas Ekonomi dan Bisnis Universitas Mataram, rosewahyu99@gmail.com
}

\begin{tabular}{ll|lll}
\hline Article history & \multicolumn{1}{l}{} \\
\hline Dikirim tanggal & $: 06 / 08 / 2020$ & Diterima tanggal & $:$ & $15 / 08 / 2020$ \\
Revisi pertama tanggal & $: 14 / 08 / 2020$ & Tersedia online tanggal & $:$ & $29 / 9 / 2020$ \\
\hline
\end{tabular}

\begin{abstract}
ABSTRAK
Penelitian ini bertujuan untuk mengetahui pengaruh brand ambassador terhadap citra merek dan keputusan pembelian sepatu merek Nike di kota Mataram. Jenis penelitian ini termasuk penelitian asosiatif karena penelitian ini bertujuan untuk mengetahui pengaruh ataupun juga hubungan antara dua variabel atau lebih. Variabel pada penelitian ini adalah brand ambassador, citra merek, dan keputusan pembelian. Metode pengumpulan data yang digunakan adalah metode sampel survey. Populasi pada penelitian ini adalah masyarakat kota Mataram yang berusia $>18$ tahun yang pernah membeli produk sepatu olahraga merek Nike minimal satu kali, dan memutuskan sendiri membeli produk sepatu Nike. Teknik pegambilan sampel purposive sampling, dengan jumlah sampel sebesar 100. Penyebaran angket secara langsung ke lokasi tempat dilakukannya penelitian. Alat analisis data yang digunakan adalah Analisis Multivariat Regression dengan menggunakan metode Partial Least Square (PLS) dan dibantu dengan alat pengolah data smartPLS 3.0. Hasil penelitian menunjukkan bahwa (1) brand ambassador berpengaruh signifikan terhadap citra merek. (2) brand ambassador berpengaruh signifikan terhadap keputusan pembelian. (3) citra merek berpengaruh signifikan terhadap keputusan pembelian.
\end{abstract}

Kata kunci: Brand Ambassador, Citra Merek, Keputusan Pembelian.

\section{ABSTRACT}

This study aims to determine the effect of brand ambassadors on brand image and the decision to purchase Nike brand shoes in the city of Mataram. This type of research includes associative research because this study aims to determine the influence or also the relationship between two or more variables. The variables in this study are brand ambassador, brand image, and purchasing decision. The data collection method used is the survey sample method. The population in this study was the people of Mataram, aged $>18$ years who had bought Nike brand sports shoes at least once, and decided to buy Nike shoes themselves. The sampling technique was purposive sampling, with a sample size of 100. Distribution of questionnaires directly to the location where the study was conducted. The data analysis tool used is Multivariate Regression Analysis using the Partial Least Square (PLS) method and assisted with smartPLS 3.0 data processing tools. The results showed that (1) brand ambassadors had a significant effect on brand image. (2) brand ambassadors have a significant effect on purchasing decisions. (3) brand image has a significant effect on purchasing decisions.

Keywords: Brand Ambassador, Brand Image, Purchasing Decision. 


\section{PENDAHULUAN}

Keputusan pembelian merupakan suatu hal yang sangat penting untuk diperhatikan karena keputusan pembelian merupakan hal yang digunakan oleh perusahaan untuk menciptakan strategi pemasaran yang akan dilakukan. Salah satu hal yang perlu diperhatikan oleh perusahaan dalam melakukan pemasaran produk yang akan dijual adalah dengan memahami kebutuhan konsumen, mengetahui keinginan konsumen dan selera dari pada konsumen. Pemahaman yang mendalam mengenai konsumen akan memungkinkan pemasar dapat mempengaruhi proses keputusan konsumen, sehingga mau membeli apa yang ditawarkan oleh pemasar (Sumarwan, 2003). Selain itu Alma (2011:96) berpendapat, bahwa Keputusan pembelian merupakan suatu keputusan konsumen yang dipengaruhi oleh ekonomi keuangan, teknologi, politik, budaya, produk, harga, lokasi, promosi, phsical evidence, people, dan process, sehingga membentuk suatu sikap pada konsumen untuk mengolah segala informasi dan mengambil kesimpulan berupa response yang muncul produk apa yang akan dibeli.

Perkembangan dunia saat ini berjalan dengan pesat yang menciptakan suatu persaingan yang semakin ketat ditambah lagi dengan banyaknya pemain yang menawarkan barang sejenis. Semua hal menjadi praktis dan sangat mudah untuk didapatkan sehingga konsumen mempunyai banyak pilihan dan bisa dengan mudah merubah keputusannya dengan merek yang lain. Salah satu upaya Nike dalam menjalankan aktivitas usaha sepatu olah raganya adalah dengan meningkatkan jumlah konsumen. Dalam era globalisasi persaingan bisnis yang semakin dinamis, kompleks dan serba tidak pasti, bukan hanya menyediakan peluang tetapi juga tantangan yang dihadapi oleh perusahaan-perusahaan untuk selalu mendapatkan cara terbaik guna merebut dan mempertahankan pangsa pasar.

Suatu merek harus memiliki strategi yang baik dan kuat dalam mengenalkan dan memasarkan produk sesuai dengan nilai jual merek yang telah ditentukan oleh produsen. Hal ini berguna untuk membangun citra merek (brand image) dan kepercayaan di mata konsumen terhadap produk yang dipasarkan. "Nike" merupakan nama perusahaan yang sudah lama terkenal, terutama produk sepatunya.

Salah satu cara Nike membangun citra mereknya dengan melakukan strategi periklanan dan sponsorship dengan menyelenggarakan kegiatan kegiatan olahraga internasional. Selain itu Nike juga menggandeng atlet dan artis terkenal sepeti Micheal jordan, Tiger Woods, Wayne Rooney, Marco Verratti, Cristiano Ronaldo, Ronaldinho, dan Roger Federer untuk bekerja sama menjadi brand ambassador sepatu Nike yang berarti Nike sudah melakukan promosi global. Dengan kegiatan ini Nike memiliki keunggulan besar dengan bersaing untuk bisa mempertahankan pasar dan melakukan ekspansi pasar ada dengan nama atau merek yang sama, seperti: rasa, bentuk, warna, atau ukuran kemasan yang baru.

Nike menggunakan atlet sebagai salah satu strategi pemasaran yang menggunakan tenik branding emosional, dengan menggunakan atlet terkenal sebagai media pemasaran Nike agar mampu menarik minat para pelanggan di seluruh dunia. Nike memiliki strategi pemasaran yang kuat untuk membangun merek yang bertujuan untuk membuat pelanggan nya loyal terhadap produk Nike karena produk tersebut mudah di ingat seperti logo swoosh dan slogan "Just Do It" yang selalu beredar. Hal inilah yang menjadikan Nike sering mendominasi pasar mengalahkan para kompetitornya sehingga Nike menjadi merek yang lebih terlihat dan dikenal oleh masyarakat di dunia, dominasi pasar Nike bisa kita lihat dalam setiap aspek, seperti sepatu dan baju yang dipakai oleh para atlet, dan tim-tim yang sudah di sponsori oleh Nike. 
Nike telah membangun citra bertahun-tahun di Indonesia dan telah menciptakan citra merek yang sangat baik dan melekat pada konsumen setianya. Penciptaan citra merek yang baik dari Nike di tunjukan dengan mensponsori beberapa olahragawan ternama, di antaranya pemain legenda basket dunia yaitu Michael Jordan pada tahun 1990 dengan memperkenalkan merek sepatu Nike Air Jordan. Dengan ini Nike ingin memberitau pada konsumen bahwa sosok seperti Tiger Woods, Cristiano Ronaldo dan Michael Jordan lah yang akan didapat sekaligus dengan ilmunya jika menggunakan produknya. Langkah ini sangat baik dalam rangka membangun citra merek positif di mata masyarakat Indonesia. Para remaja sebagai pecinta utama sport Indonesia bahkan dunia. Meningkatnya kesadaran olahraga pada masyarakat jaman sekarang yang cepat dapat dilihat dengan menjamurnya tempat olahraga seperti lapangan futsal, lapangan sepakbola, gym, jogging track, hingga lapangan bola basket. Faktanya bahwa olahraga menjadi salah satu gaya hidup yang wajib dilakukan setiap orang untuk bisa membuat tubuh menjadi tetap sehat dan bugar.

Nike menempati urutan pertama dalam Top Brand Award. Merek Top Indonesia atau Top Brand Award. Nike yang merupakan merek besar dan terkenal menempati posisi pertama dalam top brand index sepatu olahraga dari beberapa merek ternama di atas, karena Nike memiliki kualitas yang baik dan nyaman, dengan harga yang bersaing, promosi yang besar, dan citra merek yang baik untuk meningkatkan potensi pembelian konsumen atas produk - produknya. Maka menarik untuk diteliti mengenai faktor-faktor yang mempengaruhi keputusan pembelian pada produk sepatu merk Nike.

Berdasarkan uraian di atas penelitian ini berusaha menganalisis faktor faktor yang mempengaruhi keputusan pembelian sepatu merek Nike yang meliputi brand ambassador terhadap citra merek. Sehingga penulis melakukan penelitian dengan judul "Pengaruh Brand Ambassador Terhadap Citra Merek Dan Keputusan Pembelian Sepatu Nike Di Kota Mataram".

\section{Rumusan Masalah}

1. Apakah brand ambassador berpengaruh signifikan terhadap keputusan pembelian konsumen pada sepatu NIKE?

2. Apakah brand ambassador berpengaruh signifikan terhadap citra merek pada sepatu NIKE?

3. Apakah citra merek berpengaruh signifikan terhadap keputusan pembelian sepatu Nike?

\section{Tujuan Penelitian}

1. Untuk mengetahui signifikasi pengaruh brand ambassador terhadapa keputusan pembelian konsumen pada sepatu NIKE.

2. Untuk mengetahui signifikasi pengaruh brand ambassador terhadap citra merek pada sepatu NIKE.

3. Untuk mengetahui signifikasi pengaruh citra merek terhadap keputusan pembelian pada sepatu Nike

\section{KERANGKA TEORI}




\section{Keputusan Pembelian}

Keputusan pembelian merupakan salah satu tahapan dalam proses keputusan pembelian sebelum perilaku pasca pembelian. Dalam memasuki tahap keputusan pembelian sebelumnya konsumen sudah dihadapkan pada beberapa pilihan alternatif sehingga pada tahap ini konsumen akan melakukan aksi untuk memutuskan untuk membeli produk berdasarkan pilihan yang ditentukan. Berikut ini merupakan beberapa definisi keputusan pembelian menurut para ahli.

Menurut Buchari Alma (2013:96) mengemukakan bahwa keputusan pembelian adalah sebagai berikut:

"Keputusan pembelian adalah suatu keputusan konsumen yang dipengaruhi oleh ekonomi keuangan, teknologi, politik, budaya, produk, harga, lokasi, promosi, physical evidence, people dan, process. Sehingga membentuk suatu sikap pada konsumen untuk mengolah segala informasi dan mengambil kesimpulan berupa respons yang muncul produk apa yang akan dibeli".

Menurut Kotler \& Armstrong (2016:177) mendefinisikan keputusan pembelian sebagai berikut: Consumer behavior is the study of how individual, groups, and organizations select, buy, use, and dispose of goods, services, ideas or experiences to satisfy their needs and wants. yang artinya Keputusan pembelian merupakan bagian dari perilaku konsumen perilaku konsumen yaitu studi tentang bagaimana individu, kelompok, dan organisasi memilih, membeli, menggunakan, dan bagaimana barang, jasa, ide atau pengalaman untuk memuaskan kebutuhan dan keinginan mereka.

\section{Citra Merek}

Salah satu tugas perusahaan adalah menciptakan merek yang positif dimata pelanggan dimana merek merupakan salah satu hal yang harus di perhatikan oleh perusahaan untuk keberlangsungan usahanya dimasa yang akan datang.

Menurut Kertajaya (2010:63), merek disebut sebagai value indicator karena brand mampu menciptakan dan menambahkan value kepada produk, perusahaan, orang atau bahkan Negara, oleh karena itu brand menjadi indicator value yang ditawarkan kepada pelanggan internal, eksternal, dan investor. Selain itu merek mengindikasikan value dari produk, sehingga akan membuat perusahaan mampu menghindar dari jebakan komoditas.

Salah satu hal yang memegang peranan penting dalam pemasaran adalah merek. Terdapat beberapa perbedaan antara produk dengan merek. Produk merupakan sesuatu yang dihasilkan oleh pabrik dan mudah ditiru oleh para pesaing. Sedangkan merek merupakan sesuatu yang dibeli oleh kosumen, memiliki nilai dan identitas atau ciri tertentu yang dilindungi secara hukum sehingga tidak dapat ditiru oleh pesaing. Merek mempengaruhi persepsi pelanggan terhadap produk yang akan dibeli maka persaingan antar perusahaan adalah persaingan persepsi bukan produk (Tjiptono 2011:34).

Menurut undang-undang Merek no 15 tahun 2001 pasal 1 ayat 1 dalam Fandy Tjiptono (2011:3), menyatakan bahwa Merek adalah tanda yang berupa gambar, nama, kata, huruf-huruf, angka-angka, susunan warna, atau kombinasi dari unsur-unsur tersebut yang memiliki daya pembeda dan digunakan dalam kegiatan perdagangan barang atau jasa". Menurut Kotler dan Armstrong (2013:230) merek adalah "Brand is a name, term, symbol, design, or a combination of these, that identifies the products or services of one seller or group seller and differentiates them from those of competitors".

Berdasarkan definisi dari beberapa ahli tentang merek, dapat disimpulkan bahwa merek merupakan suatu bentuk identitas dari suatu produk yang ditawarkan ke pelanggan 
yang dapat membedakan produk perusahaan dari produkpesaing yang berbentuk suatu nama, kata, tanda, simbol, desain, atau kombinasi dari semua hal tersebut.

\section{Brand Ambassador}

Untuk membangun kepercayaan pada konsumen terhadap produk yang ditawarkan, setiap perusahaan harus menciptakan strategi pemasaran langsung yang dapat mempengaruhi konsumen akan suatu produk, perusahaan dapat menggunakan public figure sebagai Brand ambassador sebagai promosi dalam memasarkan produknya, tentunya konsumen akan lebih tertarik terhadap produk yang di gunakan oleh public figure yang dapat mempengaruhi keputusan pembeliannya terhadap suatu produk, berikut adalah definisi mengenai Brand ambassador. Menurut Soehadi yang dikutip Prawira (2012), menjelaskan bahwa Brand ambassador adalah seseorang yang mempresentasikan potret atau citra terbaik suatu produk. Seseorang ini biasanya dari kalangan selebriti atau orang orang popular lainya. sedangkan menurut Lea Greenwood (2012:88), "Brand ambassador ia a tool used by companies to comunnicate and conncet with the public, regarding how them actually enchances sales".

Penggunaan brand ambassador dilakukan oleh perusahaan untuk memengaruhi atau mengajak konsumen. Hal ini bertujuan agar konsumen tertarik menggunakan produk, terlebih karena pemilihan brand ambassador biasanya didasarkan pada pencitraan melalui seorang selebrititas yang terkenal (VisCAP Model dalam penelitian Devi Gita, 2012).

Berdasarkan beberapa definisi di atas dapat diartikan bahwa Brand ambassador merupakan upaya yang dilakukan oleh perusahaan untuk mempengaruhi atau mengajak konsumen dengan menggunakan selebrity sebagai ikon untuk mempresentasikan citra terbaik dari suatu produk, agar konsumen tertarik untuk menggunakan produk tersebut.

\section{Pengembangan Hipotesis}

H1 = Diduga bahwa Brand Ambassador berpengaruh signifikan terhadap Citra Merek Produk Sepatu Nike Di Kota Mataram.

H2 = Diduga bahwa Brand Ambassador berpengaruh signifikan terhadap Keputusan Pembelian Produk Sepatu Nike Di Kota Mataram.

H3 = Diduga bahwa Citra Merek berpengaruh signifikan terhadap Keputusan Pembelian Produk Sepatu Nike Di Kota Mataram.

\section{Jenis Penelitian}

\section{METODE PENELITIAN}

Jenis penelitian yang akan digunakan adalah pendekatan kuantitatif dengan penelitian asosiatif. Penelitian asosiatif merupakan penelitian yang bertujuan untuk mengetahui pengaruh ataupun juga hubungan antara dua variabel atau lebih. Penelitian ini mempunyai tingkatan tertinggi dibandingkan dengan diskriptif dan komparatif karena dengan penelitian ini dapat dibangun suatu teori yang dapat berfungsi untuk menjelaskan, meramalkan dan mengontrol suatu gejala. Dalam penelitian ini penulis ingin mengetahui pengaruh brand ambassador terhadap citra merek dan keputusan pembelian produk sepatu Nike di Kota Mataram.

\section{Sumber Data}

Sumber data yang digunakan dalam penelitian ini adalah data primer. Data primer dalam penelitian ini diperoleh dengan cara memberikan kuesioner secara pribadi kepada responden yang berkaitan. 


\section{Metode Pengumpulan Data}

Mengingat populasi yang cukup besar maka metode pengumpulan data yang digunakan dalam penelitian ini adalah metode sampel survey. Sampel survey adalah suatu prosedur dimana hanya sebagian dari populasi saja yangg diteliti dan dipergunakan untuk menggambarkan sifat seta ciri yang dikendaki dari populasi (Nasir, 1999; 325). Proses pengambilan sampel ini berdasarkan kebetulan, dimana responden dianggap cocok untuk dijadikan sampel karena memiliki kriteria yang sesuai. Dalam penelitian ini tidak semua konsumen dapat dijadikan sampel, karena akan membutuhkan waktu, tenaga, dan biaya yang cukup besar.

\section{Alat Pengumpulan Data}

Alat pengumpulan data yang digunakan dalam penelitian ini adalah kuesioner yang berupa sejumlah pertanyaan tertulis untuk memeroleh informasi dari responden dalam arti laporan tentang pribadinya atau hal-hal yang diketahuinya. Keuntungan utama menggunakan kuesioner adalah peneliti dapat mengumpulkan semua respon lengkap dalam periode waktu singkat. Kuesioner akan menghasilkan data primer yang langsung diperoleh dari responden (Sugiyono, 2014). Skala yang digunakan dalam kuesioner adalah skala likert yang dengan tujuh interval yaitu sangat tidak setuju sekali, setuju tidak setuju, kerang setuju, kurang setuju, tidak setuju, netral, setuju, sangat setuju.

\section{Waktu dan Lokasi Penelitian}

Penelitian ini dilakukan di Lombok Epicentrum Mall dan di Taman Udayana di kota Mataram pada waktu Car Free Day (CFD) di bulan Juni 2019 sampai dengan selesai. Peneliti memilih lokasi ini untuk memudahkan dalam mendapatkan responden yang sesuai dengan kriteria penelitian.

\section{Populasi Penelitian}

Populasi menunjukkan sebuah perkumpulan secara keseluruhan orang, acara atau ketertarikan terhadap sesuatu yang spesifik sehingga peneliti dapat melakukan sebuah penelitian yang ingin diteliti. Populasi merupakan sekumpulan orang, kejadian atau ketertarikan terhadap sesuatu agar peneliti dapat menarik kesimpulan (Sekaran, 2013). Pada penelitian ini, peneliti menjadikan para pengunjung Lombok Epicentrum Mall dan Taman Udayan yang menggunakan sepatu merek Nike sebagai populasi penelitian, dengan jumlah populasi yang tidak diketahui dengan pasti jumlahnya.

\section{Sampel Penelitian}

Sampel adalah subset dari populasi, terdiri dari beberapa anggota populasi (Ferdinand, 2014). Proses pengambilan sampel ini berdasarkan kebetulan, yaitu responden yang bertemu dengan peneliti namun dianggap cocok untuk dijadikan sampel karena memiliki kriteria. Teknik pengambilan sampel dengan Purposive Sampling atau pengambilan sampel berdasarkan kriteria tertentu seperti:

1. Pernah membeli produk sepatu olahraga merek Nike minimal satu kali

2. Berusia $\geq 18$ tahun

3. Responden memutuskan sendiri membeli produk sepatu Nike

Jumlah sampel yang diambil dalam penelitian ini menggunakan rumus Lemeshow, hal ini dikarenakan jumlah populasi tidah diketahui atau tidak terhingga. Berikut rumus Lameshow yaitu:

$$
\mathrm{n}=\mathrm{z} 1-\alpha / 2 \mathrm{P}(1-\mathrm{P})
$$


Keterangan :

$\mathrm{n}=$ Jumlah sampel

$\mathrm{z}=$ skor $\mathrm{z}$ pada kepercayaan $95 \%=1,96$

$\mathrm{p}=$ maksimal estimasi $=0,5$

$\mathrm{d}=$ alpha $(0,10)$ atau sampling error $=10 \%$

Melalui rumus di atas, maka jumlah sampel yang akan diambil adalah:

$$
\begin{aligned}
& \mathrm{n}=\frac{\frac{\mathrm{z}_{1-\alpha / 2}^{2} \mathrm{P}(1-\mathrm{P})}{\mathrm{d}^{2}}}{\mathrm{n}=\frac{1,962^{2} \cdot 0,5(1-0,5)}{0,1^{2}}} \\
& \mathrm{n}=\frac{3,8416 \cdot 0.25}{0.01} \\
& \mathrm{n}=96,04=100
\end{aligned}
$$

Setidaknya penulis harus mengambil data dari sampel sekurang-kurangnya sejumlah 100 orang.

Analisis Data

Penelitian ini menggunakan metode Partial Least Square (PLS) dan dibantu dengan alat pengolah data smartPLS 3.0.

\section{Uji Validitas}

\section{HASIL DAN PEMBAHASAN}

Uji validitas dilakukan guna mengetahui apakah konstrak sudah memadai untuk dilanjutkan sebagai penelitian atau tidak. Pada uji validitas ini, ada dua macam evaluasi yang dilakukan, yaitu:

\section{a. Convergent Validity}

Pada tahap ini peneliti melakukan penilaian terhadap convergent validity dari masing-masing konstrak. Convergent validity diukur dengan menggunakan parameter outer loadings dan Average Variance Extracted (AVE). Nilai loading factor yang disyaratkan,

Tabel 4.8

Average Variance Extracted (AVE)

\begin{tabular}{|l|l|}
\hline Brand Ambassador (BA) & 0,622 \\
\hline Citra Merek (CM) & 0,798 \\
\hline Keputusan Konsumen (KP) & 0,716 \\
\hline
\end{tabular}

Sumber: Data Primer Diolah, 2019

\section{b. Discriminant Validity}

Tahap berikutnya untuk menguji validitas suatu model, yaitu dengan melihat discriminant validitynya. Discriminant validity dimulai dengan melihat cross loading

Tabel 4.9 Cross Loading antara Indikator dengan Konstrak

\begin{tabular}{|l|c|c|c|}
\hline & BA & CM & KP \\
\hline BA1 & $\mathbf{0 , 8 0 9}$ & 0,731 & 0,779 \\
\hline
\end{tabular}




\begin{tabular}{|l|r|r|r|}
\hline BA2 & $\mathbf{0 , 8 3 0}$ & 0,723 & 0,722 \\
\hline BA3 & $\mathbf{0 , 7 8 0}$ & 0,704 & 0,731 \\
\hline BA4 & $\mathbf{0 , 7 4 2}$ & 0,666 & 0,669 \\
\hline BA5 & $\mathbf{0 , 7 1 6}$ & 0,651 & 0,630 \\
\hline BA6 & $\mathbf{0 , 8 0 3}$ & 0,673 & 0,689 \\
\hline BA7 & $\mathbf{0 , 7 0 9}$ & 0,601 & 0,588 \\
\hline BA8 & $\mathbf{0 , 7 0 8}$ & 0,574 & 0,621 \\
\hline BA9 & $\mathbf{0 , 8 9 3}$ & 0,878 & 0,829 \\
\hline BA10 & $\mathbf{0 , 8 7 1}$ & 0,870 & 0,826 \\
\hline CM1 & 0,877 & $\mathbf{0 , 9 0 6}$ & 0,834 \\
\hline CM2 & 0,817 & $\mathbf{0 , 9 0 0}$ & 0,824 \\
\hline CM3 & 0,789 & $\mathbf{0 , 8 8 3}$ & 0,812 \\
\hline CM4 & 0,801 & $\mathbf{0 , 8 8 1}$ & 0,839 \\
\hline CM5 & 0,777 & $\mathbf{0 , 9 0 7}$ & 0834 \\
\hline CM6 & 0,786 & $\mathbf{0 8 8 0}$ & 0,808 \\
\hline KP1 & 0,796 & 0,824 & $\mathbf{0 , 8 3 9}$ \\
\hline KP2 & 0,778 & 0830 & $\mathbf{0 , 8 7 8}$ \\
\hline KP3 & 0,653 & 0,672 & $\mathbf{0 , 7 5 6}$ \\
\hline KP4 & 0,738 & 0,724 & $\mathbf{0 , 8 1 8}$ \\
\hline KP5 & 0,748 & 0,784 & $\mathbf{0 , 8 4 4}$ \\
\hline KP6 & 0,779 & 0,826 & $\mathbf{0 , 8 8 6}$ \\
\hline KP7 & 0,749 & 0,778 & $\mathbf{0 , 8 4 2}$ \\
\hline KP8 & 0,743 & 0,785 & $\mathbf{0 , 8 5 8}$ \\
\hline KP9 & 0,776 & 0,802 & $\mathbf{0 , 8 6 8}$ \\
\hline KP10 & 0,772 & 0,791 & $\mathbf{0 , 8 5 2}$ \\
\hline KP11 & 0,803 & 0,760 & $\mathbf{0 , 8 3 8}$ \\
\hline KP12 & 0,840 & 0,792 & $\mathbf{0 , 8 8 9}$ \\
\hline
\end{tabular}

Sumber: Data Primer Diolah, 2019

Selain melihat hasil analisis cross loading, discriminant validity juga perlu dinilai dengan cara membandingkan nilai akar AVE dengan korelasi antar konstrak. Rekomendasi untuk discriminant validity yang terbaik adalah nilai akar AVE harus lebih besar dari korelasi antar konstrak.

Tabel 4.10 Korelasi antar Konstrak (Akar AVE)

\begin{tabular}{|l|c|c|c|c|}
\hline & (LK) & (CS) & (SQ) & AVE \\
\hline (BA) & $\mathbf{0 . 7 8 9}$ & & & 0,622 \\
\hline (CM) & 0,905 & $\mathbf{0 . 8 9 3}$ & & 0,798 \\
\hline (KP) & 0,905 & 0.924 & $\mathbf{0 . 8 4 6}$ & 0,716 \\
\hline
\end{tabular}

Sumber: Data Primer Diolah, 2019

Berdasarkan tabel 4.10 dapat dikatakan bahwa akar AVE pada semua konstrak lebih rendah dari pada korelasi antar variabel. Dari hasil tersebut dapat disimpulkan bahwa seluruh variabel memiliki discriminant validity yang baik.

\section{Uji Reliabilitas}

156 | Pengaruh Brand Ambassador Terhadap Citra Merek dan Keputusan ... 
Uji reliabilitas dapat dilihat dari nilai cronbach's alpha dan composite reliability. Keduanya dikatakan reliabel apabila nilainya lebih dari 0,7. Hasil dari pengujian tersebut dapat dilihat pada tabel berikut.

Tabel 4.11 Cronbach's Alpha dan Composite Reliability

\begin{tabular}{|c|c|c|c|}
\hline & $\begin{array}{c}\text { Cronbach's } \\
\text { Alpha }\end{array}$ & rho_A & $\begin{array}{c}\text { Composite } \\
\text { Reliability }\end{array}$ \\
\hline (BA) & 0.932 & 0.938 & 0.942 \\
\hline (CM) & 0.949 & 0.950 & 0.959 \\
(KP) & 0.964 & 0.965 & 0.968 \\
\hline
\end{tabular}

Sumber: Data Primer Diolah, 2019

Berdasarkan tabel 4.11 dapat disimpulkan bahwa nilai cronbach'salpha untuk semua konstrak paling rendah bernilai 0,932, yaitu pada konstrak BA. Sedangkan untuk nilai composite reliability terendah terdapat pada konstrak BA juga dengan nilai 0,942 . Hasil tersebut menunjukkan bahwa instrumen penelitian ini reliabel kar Pengujian Inner Model (Model Struktural)

Pengujin ini dilakukan untuk uji hipotesis. Model struktural dapat dievaluasi dengan melihat $\mathrm{R}^{2}$ (reliabilitas indikator) untuk konstrak dependen dan nilai t-statistik dari pengujian koefisien jalur (path coefficient). Semakin tinggi nilai $\mathrm{R}^{2}$ berarti semakin baik model prediksi dari model penelitian.

\section{Uji Determinasi atau Analisis Varians $\left(\mathbf{R}^{2}\right)$}

Tabel 4.12 Nilai $\mathrm{R}^{2}$

\begin{tabular}{|l|r|rr|}
\hline & R Square & \multirow{2}{*}{ R Square } & \\
& & Adjusted & \\
\cline { 1 - 2 } Citra Merek (CM) & 0.819 & & 0.818 \\
\hline Keputusan Pembelian (KP) & 0.880 & & 0.877 \\
\hline
\end{tabular}

Sumber: Data Primer Diolah, 2019

Berdasarkan tabel 4.12 menunjukkan bahwa brand ambassador, citra merek dan keputusan pembelian mampu menjelaskan variabilitas konstrak citra merek sebesar $81.8 \%$, sisanya $18.2 \%$ diterangkan oleh konstrak lainnya diluar yang diteliti dalam penelitian ini. Sedangkan brand ambassador terhadap citra merek dan keputusan pembelian mampu menjelaskan variabilitas konstrak kepuasan konsumen sebesar $88,0 \%$, sisanya $12 \%$ diterangkan oleh konstrak lainnya yang diluar yang diteliti dalam penelitian ini.

\section{Uji Hipotesis}

Uji Hipotesis dilakukan berdasarkan hasil uji model struktural (inneer model) yang meliputi output $\mathrm{R}^{2}$, koefisien parameter dan t-statistik. Untuk melihat apakah suatu hipotesis itu dapat diterima atau ditolak diantaranya dengan memperhatikan nilai signifikansi antar konstrak, t-statistik, dan p-values. Dengan menggunkan smart PLS 3.0 yang peneliti gunakan, nilai-nilai tersebut dapat dilihat dari hasil bootstrapping. Rules of thumb yang digunakan adalah $\mathrm{t}$-statistik $>1,94$ dengan tingkat signifikansi atau p-value 
$<0,05(5 \%)$ dan beta bernilai positif. Hasil uji hipotesis penelitian dapat dilihat dalam tabel 4.12 .

Tabel 4.13 Path Coefficient

\begin{tabular}{|c|c|c|c|c|c|}
\hline Hipotesis & $\begin{array}{c}\text { Beta } \\
(\boldsymbol{\beta})\end{array}$ & $\begin{array}{c}\text { Sample } \\
\text { Mean } \\
(\mathbf{M})\end{array}$ & $\begin{array}{c}\text { Standard } \\
\text { Deviation } \\
\text { (STDEV) }\end{array}$ & $\begin{array}{c}\text { T Statistics } \\
(|\mathbf{O} / \mathbf{S T D E V}|)\end{array}$ & P Values \\
BA -> CM & 0.905 & 0.908 & 0,017 & 51,950 & 0.000 \\
\hline BA -> KP & 0.905 & 0.908 & 0.021 & 42.770 & 0.000 \\
\hline CM -> KP & 0.580 & 0.564 & 0.110 & 5.260 & 0.000 \\
\hline
\end{tabular}

Sumber: Data Primer Diolah, 2019

Hipotesis pertama menguji apakah brand ambassador secara positif berpengaruh terhadap citra merek. Hasil pengujian menunjukkan bahwa nilai koefisien beta BA terhadap CM sebesar 0,905 dan t-statistik sebesar 51,950. Dari hasil ini dinyatakan t-tabel signifikan. karena $>1,94$ dengan p-value sebesar $0,000<0,05$ sehingga hipotesis diterima. Hal tersebut membuktikan bahwa brand ambassador terbukti memiliki pengaruh positif terhadap citra merek.

Hipotesis kedua menguji apakah brand ambassador (BA) secara positif berpengaruh keputusan pembelian (KP). Hasil menunjukkan nilai koefisien beta BA terhadap KP sebesar 0,905 dan t-statistik sebesar 42,770. Hasil tersebut menyatakan ttabel signifikan karena $>1,94$ dengan p-value sebesar $0,001<0,05$ sehingga hipotesis diterima. Hal tersebut menunjukkan bahwa brand ambassador terbukti berpengaruh positif terhadap keputusan pembelian.

Hipotesis ketiga menguji apakah citra merek (CM) secara positif berpengaruh terhadap keputusan pembelian (KP). Hasil pengujian menunjukkan bahwa nilai koefisien beta CM terhadap KP sebesar 0,580 dan t-statistik sebesar 5,260. Dari hasil tersebut dinyatakan t-tabel signifikan karena $>1,94$ dengan $p$-value sebesar $0,000<0,05$ sehingga hipotesis diterima. Dengan demikian, citra merek terbukti berpengaruh positif terhadap keputusan pembelian.

\section{Ringkasan Hasil Pengujian Hipotesis}

Tabel 4.14 Hasil pengujian hipotesis

\begin{tabular}{|l|l|l|c|}
\hline \multicolumn{2}{|c|}{ Hipotesis } & \multicolumn{1}{c|}{ Hasil } & Status \\
H1 & BA secara positif berpengaruh & $\square$ Koef. beta $=0.905$ & \\
& terhadap CM & $\square$ T-statistik $=51.950$ & Diterima \\
\hline & $\begin{array}{l}\text { P-value }<0.05(0.000) \\
\mathbf{H}_{2}\end{array}$ & $\square$ Koef. beta $=0.905$ & \\
& BA secara positif berpengaruh & $\square$ T-statistik $=42.770$ & Diterima \\
\hline terhadap KP & $\square$ P-value $<0.05(0.001)$ & \\
\hline H3 & $\begin{array}{l}\text { CM secara positif berpengaruh } \\
\text { terhadap KP }\end{array}$ & $\square$ Koef. beta $=0.580$ & Diterima
\end{tabular}

158 | Pengaruh Brand Ambassador Terhadap Citra Merek dan Keputusan ... 


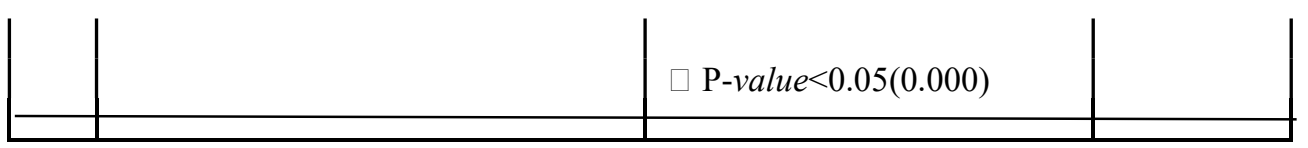

Sumber : Data Primer Diolah, 2019

\section{PEMBAHASAN}

\section{Pengaruh Brand Ambassador (BA) terhadap Citra Merek (CM)}

Hasil penelitian menunjukkan bahwa Brand Ambassador (BA) memiliki pengaruh positif yang signifikan terhadap Citra Merek (CM). Hasil ini mengindikasikan bahwa semakin sesuai BA yang digunakan prusahaan dengan kriteria konsumen maka, akan semakin meningkatkan CM. Hasil penelitian ini sejalan dengan penelitan yang dilakukan Panji Eka Prasetyo (2016), yang menyatakan bahwa Brand ambassador berpengaruh positif dan signifikan terhadap Citra Merek. Dengan demikian dapat dikatakan bahwa terdapat pengaruh positif BA terhadap CM.

\section{Pengaruh Brand Ambassador (BA) terhadap Keputusan Pembelian (KP)}

Selanjutnya dari hasil analisis data yang sudah dilakukan (BA) berpengaruh positif yang signifikan terhadap Keputusan Pembelian (KP). Hasil penelitian ini sejalan dengan penelitian sebelumnya yang dilakukan oleh Magdalena (2015) dengan judul penelitian "Pengaruh Brand Ambassador terhadap international brand image serta Dampaknya terhadap Keputusan Pembelian (Studi pada Pengguna Smartphone Samsung)" menunjukkan hasil brand ambassador berpengaruh positif dan signifikan pada variabel keputusan pembelian. Dengan demikian dapat dikatakan bahwa terdapat pengaruh positif BA terhadap KP.

\section{Pengaruh Citra Merek (CM) terhadap Keputusan Pembelian (KP)}

Serupa dengan Brand Ambassador (BA), Citra Merek (CM) memiliki pengaruh positif yang signifikaan terhadap Keputusan Pembelian (KK). Keputusan pembelian juga dipengaruhi oleh citra merek. Citra suatu merek dimata konsumen merupakan salah satu elemen penting dalam proses menentukan keputusan pembelian. Sebab merek merupakan salah satu sumber informasi yang digunakan sebagai acuan baik atau buruknya suatu produk. Fransisca (2010) dalam penelitiannya menyimpulkan bahwa citra merek memiliki pengaruh yang signifikan terhadap keputusan pembelian. Hal ini dapat di artikan bahwa citra yang baik akan suatu produk akan mempengaruhi konsumen untuk membeli produk tersebut, begitu juga sebaliknya. Citra yang buruk akan suatu produk akan mempengaruhi konsumen sehingga konsumen tidak membeli produk tersebut. Hasil penelitian ini mendukung penelitian sebelumnya yang dilakukan oleh Putra (2014) dengan judul penelitian "Pengaruh Brand Ambassador terhadap Brand Image serta Dampaknya terhadap Keputusan Pembelian (Survey Pada Pengguna LINE di Asia)". Hasil penelitian menunjukkan bahwa variabel brand image berpengaruh signifikan terhadap keputusan pembelian. Dengan demikian dapat dikatakan bahwa terdapat pengaruh positif CM terhadap KP. 
Dari uraian ini menjunjukan bahwa Brand Ambassador bisa berpengaruh langsung terhadap keputusan pembelian atau tidak berpengaruh langsung terhadap keputusan pembelian (dimediasi oleh citra merek). Dibuktikan dari Brand Ambassador (0.380) X Keputusan Pembelian $(0.880)=0.334$, Brand Ambassador (0.905) X Citra Merek (0.819) $=0.741$. Hal ini membuktikan bahwa selain berpengaruh secara langsung brand ambassador juga berpenggaruh terhadap keputusan pembelian dengan menentukan brand image jika kita bandingkan besarnya pengaruh langsung dengan indikator variabel mediasi (brand image) menunjukkan bahwa pengaruh melalui brand image lebih besar. Hal ini berimplikasi pada pentingnya pemilihan brand ambassador yang mampu meningkatkan brand image dan pada akhirnya mempengaruhi keputusan pembelian.

\section{KESIMPULAN}

Berdasarkan hasil pembahasan maka dapat disimpulkan sebagai berikut:

1. Brand Ambassador berpengaruh signifikan terhadap Citra Merek sepatu olahraga merek Nike. Semakin sesuai brand ambassador yang digunakan maka semakin baik pula citra merek produk sepatu olahraga merek Nike.

2. Brand Ambassador berpengaruh signifikan terhadap Keputusan Pembelian sepatu olahraga merek Nike. Semakin baik brand ambassador yang digunakan oleh produk sepatu olahraga merek Nike ini maka keputusan pembelian ini semakin tinggi.

3. Citra Merek berpengaruh signifikan terhadap Kepuutusan Pembelian sepatu olahraga merek Nike. Semakin baik citra merek produk sepatu olahraga Nike ini makan keputusan pembelian ini semakin tinggi.

\section{REFERENSI}

Akbar, Adam. 2012. Analisis Pengaruh Citra Merek, Harga, dan Kualitas Produk Terhadap Keputusan Pembelian Notebook Toshiba. Fakultas Ekonomi. Universitas Gunadarma.

Ananda, Kiki Dwi Putri. 2018. "Pengaruh Citra Merek Terhadap Keputusan Pembelian (Studi Pada Pembelian Handphone Merek Oppo di Kota Mataram”. Skripsi. Mataram: Universitas Mataram

Evita, Nurul. 2017. "Pengaruh Citra Merek Terhadap Pembelian (Studi Kasus Pada Bakso Boedjangan Cabang Burangrang Bandung)". Skripsi. Bandung: Universitas Telkom

Fatlahah, Aniek. 2013. "Pengaruh Kualitas Produk Dan Citra Merek Terhadap Keputusan Pembelian Es Krim Wall's Magnum". Jurnal

Fernidand, Augusty. 2006. Metode Penelitian Manajemen. Semarang. Universitas Diponegoro

Fristiana, Dessy Amelia. 2012. "Pengaruh Citra Merek Dan HargaTerhadap Keputusan Pembelian Pada Ramai Swalayan Peterongan Semarang”. Jurnal

Ghozali, Imam. 2006. Aplikasi Analisis Multivariate Dengan Program SPSS. Cetak Keempat Semarang: Badan Penerbit Universittas Diponegoro

Hartanti, Aprita. 2018. "Pengaruh Penggunaan Brand Ambassador Maudy Ayunda Terhadap Brand Image Quipper Video". Skripsi. Jakarta: Universitas Bakrie

Kotler dan Keller. 2009. Manajemen Pemasaran. Jilid I, Edisi 13. Jakarta: Erlangga

160 | Pengaruh Brand Ambassador Terhadap Citra Merek dan Keputusan ... 
Kotler, Philip. 2002. Manajemen Pemasaran. Edisi Milenium. Jilid I. Jakarta: PT.

Indeks Kelompok Gramedia

Miharman, Sastia Pandu. 2019. "Peran Customer Relationship Marketing Dan Service Quality Terhadap Loyalitas Konsumen Melalui kepuasan Konsumen: Studi Pada Maskapai Penerbangan Garuda". Skripsi. Mataram: Universitas Mataram.

Mardiyah, Nihayatul. 2010. Pengaruh Brand Ambassador Terhadap Brand Image

Sabun Lux (Studi di Pondok Pesantren Wahid Hasyim Yogyakarta). Skripsi. Yogyakarta: Universitas Negeri Sunan Kalijaga Yogyakarta.

Nuraini, Alfiah. 2015. Pengaruh Celebrity Endorser Dan Kualitas Produk Terhadap Keputusan Pembelian Melalui Citra Merek Pada Kosmetik Wardah di Kota Semarang. Skripsi. Semarang: Universitas Negeri Semarang.

Nurdiansyah, Dedi. 2017. Pengaruh Kualitas Produk dan Harga Terhadap Keputusan Pembelian Produk Sepatu Olahraga Merek Adidas Di Bandar Lampung. Skripsi. Bandar Lampung: Universitas Lampung.

Oktaviary, Husna Dwi. 2018. "Pengaruh Motivasi, Suasana Toko, Dan Kelengkapan Barang Terhadap Keputusan Pembelian Konsumen Pada Guardian Lombok Epicentrum Mall Mataram". Skripsi. Mataram: Universitas Mataram

Prasetyo, Panji Eka. 2016. "Brand Ambassador Dan PengaruhnyaTerhadap Keputusan Pembelian Yang Dimediasi Oleh Citra Merek (Studi Kasus Pada XL Axiata Di Pelajar Dan Mahasiswa Yogyakarta)". Skripsi. Yogyakarta: Universitas Negeri Yogyakarta

Putra, Muhammad Ikhsan. 2014. "Pengaruh Brand Ambassador Terhadap Brand Image Serta Dampaknya Terhadap Keputusan Pembelian (Survey pada pengguna LINE di Asia)". Skripsi

Ramadhani, Aditya. 2011.Pengaruh Faktor Psikologis terhadap Keputusan Pembelian Sepeda Motor Merek Yamaha. Fakultas Ekonomi. Universitas Gunadarma.

Rahma, Eva Sheilla. 2007. Analisis Pengaruh Kualitas Layanan dan Citra Merek terhadap Minat Beli dan Dampaknya pada Keputusan Pembelian (Studi Pada Pengguna Telepon Seluler Merek Sony Ericson di KotaSemarang). Tesis. Semarang: Universitas Diponegoro.

Rizan, Mohammad. Basrah Saidani \&Yusiyana Sari. 2012. Pengaruh Brand Image dan Brand Trust terhadap Brand Loyalty Teh Botol Sosro (Survei Konsumen Teh Botol Sosro di Food Court ITC Cempaka Mas, Jakarta timur). Jurnal Riset Manajemen Sains Indonesia (JRMSI) |Vol. 3, No. 1, 2012.

Romadhoni, Muhammad. 2015. Pengaruh Citra Merek (Brand Image) Terhadap Pengambilan Keputusan Sepatu Nike Pada Mahasiswa FIK UNY. Skripsi. Yogyakarta: Universitas Negeri Yogyakarta.

Sagala, Mohammad Habib dan Hendrati Mulyaningsih. "Pengaruh Brand Ambassador Terhadap Brand Image OPPO Smarthphone Di Kota Bandung". Jurnal

Santoso, Tri Iman. 2013. Pengaruh Asosiasi Merek, Citra Merek, dan Sikap Merek Terhadap Ekuitas Merek (Studi Kasus Pada CV. ALKA Yogyakarta). Skripsi. Yogyakarta: Universitas Negeri Yogyakarta. 
Sugiyono. 2005. Metode Penelitian Bisnis. Bandung: Alfabeta . 2011. Statistika untuk Penelitian. Bandung: CV Alfabeta.

Shiffman, Leon G dan Kanuk, Lesli Lazar. 2008. Perilaku Konsumen. Jakarta: PT. Indeks Kelompok Gramedia

Utomo, Gigih Wahyu dan Bulan Prabawani. 2016. "Brand Ambassador dan Citra Merk terhadap Keputusan Pembelian Sepeda Motor Suzuki Type Nex”. Jurnal 